\title{
Bond strength values of fiberglass post to flared root canals reinforced with different materials
}

Thaís Emanuelle BAKAUS(a) Yançanã Luizy GRUBER(a) Alessandra REIS(a) Osnara Maria Mongruel GOMES(a) Giovana Mongruel GOMES(a)

(a) Universidade Estadual de Ponta GrossaUEPG, School of Dentistry, Department of Restorative Dentistry, Ponta Grossa, PR, Brazil.

Declaration of Interest: The authors certify that they have no commercial or associative interest that represents a conflict of interest in connection with the manuscript.

\section{Corresponding Author:}

Giovana Mongruel Gomes

Email: giomongruel@gmail.com

https://doi.org/10.1590/1807-3107bor-2018.vol32.0013

Submitted: May 25, 2017

Accepted for publication: January 08, 2018

Last revision: January 18, 2018

\begin{abstract}
The aim of this study was to compare in vitro the bond strength (BS) between fiberglass posts and flared root canals reinforced with different materials. The roots of 48 premolars were endodontically treated. After one week, the root canals were prepared to simulate an oversized root canal, except for the positive control group (PCG), which was cemented with a prefabricated fiber post (PFP) compatible with the root canal size, simulating an ideal adaptation. The other samples ( $n=8$ /group) were used to test alternative restorative techniques for filling root canals: negative control group (NCG [PFP with a smaller diameter than of the root canal]), composite resin group - CRG, bulkfill group - BFG, self-adhesive cement group - SAG, and glass ionomer group - GIG. The posts were cemented and after 1 week, each root was sectioned transversely into six 1-mm thick discs and the push-out test was done to evaluate the BS. Data were analyzed by two-way repeated measures ANOVA and Tukey's tests $(\alpha=0.05)$. The highest BS value was observed for PCG. The NCG and the GIG groups showed the lowest BS values. Root reinforcement with conventional and bulk-fill composite resins showed the highest BS values; however, the bulk-fill resin was the only treatment able to maintain high BS values in all regions of the root canal. The self-adhesive cement showed intermediate results between CRG and GIG. Root reinforcement with bulk-fill composite resin is an effective option for flared root canals before cementation of a prefabricated fiber post.
\end{abstract}

Keywords: Resin Cements; Shear Strength.

\section{Introduction}

Posts and cores of cast metal alloy can adapt intimately to the remaining root structure but study findings have shown that the produced wedging effect under the action of occlusal forces, associated with the high modulus of elasticity of metal post ${ }^{1}$ can lead to catastrophic fractures of the roots. ${ }^{2}$ Thus, fiberglass posts have substantially replaced metallic posts for intraradicular retainers, as they have a modulus of elasticity similar to dentin, ${ }^{1}$ reducing the number of root failures. ${ }^{3}$

However, because fiberglass posts are pre-fabricated, they do not always adapt well to the root canal. Root canals can exhibit a large opening due to extensive involvement of carious lesions, previous restorations with post and 
core of high diameters, endodontic over-instrumentation, incomplete physiological root formation, internal resorption, traumatic dental injuries or even root canals with an oval shape. ${ }^{4}$ In the presence of flared root canals, one may expect a mismatch between the root canal and post diameters. The polymerization shrinkage that results from thick layers of resin cement can induce structural discontinuities at the dentin/ cement and cement/post interfaces such as bubbles, gaps, and fissures, which in turn, are responsible for a reduced retention of posts to root canals. ${ }^{5}$

Although the ideal thickness of the resin cement for glass fiber post cementation remains unknown, prospective and retrospective clinical studies indicate that a higher frequency of debonded fiberglass posts occurs when the thickness of the cement layer is larger. ${ }^{5}$

Thus, some alternatives for reducing the layer of the resin cement have been suggested in the literature such as the use of accessory fiber posts, ${ }^{6}$ direct and indirect anatomical post ${ }^{6,7,8,9}$ and root reinforcement with a restorative material. ${ }^{8,10,11}$ Theoretically, the latter approach seems to be promising; however, the study by Gomes et al. ${ }^{8}$ reported that root reinforcement with a conventional light-cured composite resin showed very low bond strength values, which could be attributed to inadequate polymerization in the deeper regions of the root canal, ${ }^{11}$ affecting the material properties. ${ }^{12}$

Some studies report the use of conventional composite resins for root reinforcement. ${ }^{8,13}$ Nevertheless, little information exists about the use self-adhesive resin cements. These materials are dual cure and, therefore, polymerize without light, which does not reach the apical region of the root canal. Additionally, the technique is less sensitive $\mathrm{e}^{14,15}$ as it eliminates the need of acid etching and bonding steps.

Recently, a new class of composite resins named bulk-fill resins has been introduced in the market. The new material has adequate degree of conversion, ${ }^{16}$ and microhardness, ${ }^{17,18}$ low volumetric shrinkage ${ }^{19}$ and a high depth of cure, ${ }^{20}$ and could be an alternative to conventional composite resins for root reinforcement. . $^{16,17,18,21,22,23,24}$

However, published studies with bulk-fill resins were performed in coronal dentin and no study has investigated their performance for reinforcement of flared root canals. Therefore, the aim of this study was to compare the bond strength values of fiberglass post bonded to flared root canals reinforced with different materials.

Thenull hypotheses tested were: a) different materials used to restore flared root canals prior to fiber post cementation and post adaptation do not influence the bond strength values and $b$ ) the bond strength values obtained with different materials used to restore flared root canals are not influenced by the root canal regions.

\section{Methodology}

The Ethics Committee of the local university approved this study (protocol 625.407). Forty-eight extracted human mandibular premolars were stored in distilled water at $4^{\circ} \mathrm{C}$ and used within 6 months after extraction (ISO 11405:2003). ${ }^{25}$ To be included in the study sample, teeth had to be sound, without root cracks and severe root curvatures and not submitted to previous endodontic treatment. Additionally, teeth had to have a root length of $14 \pm 1 \mathrm{~mm}$, measured from the cement-enamel junction (CEJ).

\section{Specimen preparation}

\section{Endodontic treatment}

Teeth were transversally sectioned at the CEJ using a low-speed diamond saw (Isomet 1000, Buehler, Lake Bluff, USA). Endodontic access was made using a tapered fissure bur with a high-speed handpiece and water spray. Working length was established by inserting a \#10 Flexofile into each canal until it was visible at the apical foramen, then one millimeter was subtracted from this length. A crown-down technique was used for instrumentation with Gates Glidden drills \#2 to \#4. Apical enlargement was performed to size 40 and $0.06^{\circ}$ taper. Irrigation was performed after every change of instrument by alternating $1 \mathrm{~mL}$ of $1 \% \mathrm{NaOCl}$ solution and $17 \%$ EDTA solution. Roots were dried with paper points (Dentsply Maillefer, Petrópolis, Brazil), filled with vertical compaction of warm gutta-percha and resin-based sealer (AH Plus, Dentsply, Konstanz, Germany). The root access was temporarily filled with conventional glass ionomer cement (Vitro Fil, DFL, Rio de Janeiro, Brazil) and the roots were stored at $37^{\circ} \mathrm{C}$ for one week. 


\section{Post space preparation}

After one week, the roots of 8 teeth were prepared to receive a \#0.5 glass fiber post with a low speed motor (Whitepost DC, FGM, Joinville, Brazil), with a crown diameter of $1.4 \mathrm{~mm}$. This group was considered the positive control group, so the corresponding drill of the \#0.5 post was used for canal preparation, simulating a perfect adaptation of the post into the cavity.

The root canals of the remaining 40 teeth were enlarged with a \#4137 conical diamond bur (KG Sorensen, Barueri, Brazil) with $2.6 \mathrm{~mm}$ crown diameter adapted at low speed. After root canal widening, the canal walls were prepared slightly with the drill corresponding to the \#0.5 post at low speed (Whitepost DC, FGM, Joinville, Brazil) in order to standardize the smear layer. After post space preparations, the canals were irrigated with $10 \mathrm{~mL}$ of distilled water and dried with paper points. The working length was $10 \mathrm{~mm}$ for all teeth, respecting the apical limit of $4 \mathrm{~mm}$ for the endodontic filling material. One bur was used for only six preparations.

\section{Experimental groups}

The detailed composition, batch number and mode of application of the materials employed are listed in Table 1. A total of 6 experimental conditions $(\mathrm{n}=8$ each) were tested as follows:

Positive control group $(\mathrm{n}=8)$ : Prefabricated glass fiber posts of \#0.5 size, with a diameter compatible to the root canal were cemented into the roots, simulating an ideal adaptation of the post.

Negative control group $(\mathrm{n}=8)$ : The same prefabricated glass fiber posts were cemented in the flared root canals, simulating an inadequate adaptation of the post.

Root reinforcement with a flowable conventional composite resin $(n=8)$ : Root dentin walls were etched with 37\% phosphoric acid gel (Total Etch, IvoclarVivadent, Schaan, Liechtenstein) for $15 \mathrm{~s}$, followed by rinsing with water and drying with paper points. The two-step etch-and-rinse bonding agent (Tetric N-Bond, Ivoclar-Vivadent, Schaan, Liechtenstein) was applied on the entire canal surface in two coats as recommended by the manufacturer with the aid of a microbrush. After solvent evaporation, the adhesive was light-cured by positioning the tip of the light-curing unit at the canal entrance for $10 \mathrm{~s}$. A flowable conventional composite resin (Tetric N-Flow, Ivoclar-Vivadent, Schaan, Liechtenstein) was applied with a long, thin and metallic point provided by the manufacturer to fill the root canal from the apex to the cervical portion and avoid air pockets. After this, the \#0.5 prefabricated glass fiber post was lubricated with the hydrosoluble gel (KY, Johnson \& Johnson, São José dos Campos, Brazil) and was inserted into the canal. The fiber post was subsequently removed from the cavity and completely dipped into the resin. After removal of the excess resin, the tip of the lightcuring unit was placed over the post and activated for $20 \mathrm{~s}$. The fiber post was dislodged from the canal again, leaving the space ready for cementation of the prefabricated fiber post. Without the post, the resin was additionally light-cured for $20 \mathrm{~s}$.

Root reinforcement with a bulk-fill composite resin $(n=8)$ : The same procedures of the previous group were performed. However, the adhesive system Adhese ${ }^{\circledR}$ Universal (Ivoclar-Vivadent, Scchann, Liechtenstein) was used in the etch-and-rinse manner along with the composite resin Tetric ${ }^{\circledR}$ EvoFlow Bulk Fill (Ivoclar-Vivadent, Schaan, Liechtenstein).

Root reinforcement with a self-adhesive resin cement $(\mathrm{n}=8)$ : Root dentin walls were irrigated with $\mathrm{NaOCl}$ $2.5 \%$ and distilled water, followed by air drying and paper points to remove excess moisture. Then, the root canal was filled with the self-adhesive resin cement (SpeedCEM, Ivoclar-Vivadent, Scchann, Liechtenstein) using the intracanal tip of the self-mixing syringe from the apex to the cervical portion to avoid air pockets. After this, the same procedures of the previous groups were performed. Without the post, the resin cement was additionally light-cured for $20 \mathrm{~s}$.

Root reinforcement with a conventional glass ionomer $(\mathrm{n}=8)$ : Root dentin walls were etched with Ketac Conditioner (3M ESPE, St. Paul, USA) for $10 \mathrm{~s}$, followed by rinsing with water and drying with paper points. Then, the liquid and powder components of the glass ionomer (Ketac-Fil Plus, 3M ESPE, St. Paul,USA) were measured in $1 / 1$ proportions and mixed for 1 $\mathrm{min}$. The root canal was filled with the paste using a Centrix syringe from the apex to the cervical portion to avoid air pockets (DFL, Rio de Janeiro, Brazil). After, the \#0.5 prefabricated glass fiber post was lubricated with the hydrosoluble gel (KY, Johnson \& 
Johnson) and was inserted into the canal. The fiber post was subsequently removed from the post cavity and again dipped completely into the glass ionomer material; the excess ionomer was removed. After the initial curing of the glass ionomer, the fiber post was removed of the root canal, and the material was left undisturbed for $7 \mathrm{~min}$ for initial curing.

In the root reinforcement groups, root canals and the fiber posts were abundantly rinsed with water to remove the lubricant gel. The post spaces were slightly re-prepared with the drill that corresponded to the \# 0.5 fiberglass post.

\section{Post luting procedures}

Before the cementation procedures, each fiberglass post was horizontally sectioned with a water-cooled diamond rotary cutting instrument, so that a total length of $13 \mathrm{~mm}$ remained. The fiber posts were cleaned with $70 \%$ alcohol for $5 \mathrm{~s}$. Ten millimeters of the post length were cemented in the root canal,

Table 1. Composition, classification and batch number of the materials.

\begin{tabular}{|c|c|c|c|}
\hline Material / Manufacture & Classification & Composition & Batch number \\
\hline $\begin{array}{l}\text { Total-Etch / } \\
\text { Ivoclar Vivadent }\end{array}$ & Etching conditioner & $\begin{array}{c}\text { Contains phosphoric acid ( } 37 \% \text { wt in water), thickening } \\
\text { agent and pigments. }\end{array}$ & P56449 \\
\hline $\begin{array}{l}\text { Excite }^{\circledR} \text { DSC / } \\
\text { Ivoclar Vivadent }\end{array}$ & $\begin{array}{l}\text { Adhesive system } \\
\text { (dual-curing) }\end{array}$ & $\begin{array}{l}\text { Excite }{ }^{\circledR} \text { DSC contains HEMA, dimethacrylates, phosphonic acid acrylate, } \\
\text { highly dispersed silicon dioxide, initiators and stabilizers in an alcohol } \\
\text { solution. The Excite }{ }^{\circledR} \text { DSC Brush is coated with initiators. }\end{array}$ & N01061 \\
\hline $\begin{array}{l}\text { Tetric }^{\circledR} \mathrm{N} \text {-Bond / } \\
\text { Ivoclar Vivadent }\end{array}$ & $\begin{array}{l}\text { Adhesive system } \\
\text { (light-curing) }\end{array}$ & $\begin{array}{l}\text { Contains phosphoric acid acrylate, HEMA, Bis-GMA, urethane } \\
\text { dimethacrylate, ethanol, film-form agent, catalysts and stabilizers. }\end{array}$ & N64295 \\
\hline $\begin{array}{l}\text { Adhese }^{\circledR} \text { Universal / } \\
\text { Ivoclar Vivadent }\end{array}$ & $\begin{array}{l}\text { Adhesive system } \\
\text { (light-curing) }\end{array}$ & $\begin{array}{l}\text { Contains methacrylates, ethanol, water, highly dispersed } \\
\text { silicon dioxide, initiators and stabilizers. }\end{array}$ & U18658 \\
\hline
\end{tabular}

$\begin{array}{lcc}\text { Conventional } & \begin{array}{c}\text { Contains 36\% wt dimethacrylates (including TEGDMA), 63\% wt. fillers (barium } \\ \text { glass, ytterbium trifluoride, highly dispersed silica and mixed oxide) and } 1 \% \text { wt } \\ \text { Tetric }{ }^{\circledR} \text { N-Flow / }\end{array} \\ \begin{array}{c}\text { catalysts, stabilizers and pigments. The total content of inorganic fillers is } 39 \% \\ \text { volar Vivadent } \\ \text { vol. The particle size of inorganic fillers is between } 40 \text { and } 3000 \mathrm{~nm} .\end{array}\end{array}$

Contains 20-21\% weight dimethacrylates, $79-81 \%$ weight fillers (barium glass, ytterbium trifluoride, mixed oxide and prepolymer) Additional $\begin{aligned} & \text { Tetric }{ }^{\circledR} \text { EvoFlow Bulk Fill / } \\ & \text { Ivoclar Vivadent }\end{aligned} \quad \begin{gathered}\text { Bulk-fill Composite resin } \\ \text { (light-curing) }\end{gathered} \quad \begin{gathered}\text { contents: additives, catalysts, stabilizers and pigments }(<1.0 \% \text { weight). } \\ \text { The total content of inorganic fillers is } 76-77 \% \text { weight or } 53-54 \% \text { volume }\end{gathered}$ Ivoclar Vivadent $\quad$ (light-curing) The total content of inorganic fillers is $76-77 \%$ weight or $53-54 \%$ volume.
The particle size of the inorganic fillers is between $40 \mathrm{~nm}$ and $3,000 \mathrm{~nm}$ with a mean particle size of $550 \mathrm{~nm}$.

Contains 36\% wt dimethacrylates (including TEGDMA), 63\% wt. fillers (barium

The monomer matrix is composed of Bis-GMA, urethane dimethacrylate, and triethylene glycol dimethacrylate. The inorganic fillers are barium

Variolink ${ }^{\circledR}$ II / Resin cement Ivoclar Vivadent (dual-curing) glass, ytterbium trifluoride, Ba-Al-fluorosilicate glass, and spheroid mixed oxide. Additional contents: catalysts, stabilizers, and pigments. The particle size is $0.04-3.0 \mu \mathrm{m}$. The mean particle size is $0.7 \mu \mathrm{m}$.

N74353
The monomer matrix is composed of dimethacrylates and acidic monomers. The inorganic fillers are barium glass, ytterbium trifluoride,

U09053
$\mathrm{Ketac}^{\top M}$ Fil Plus / 3M ESPE
N44255 co-polymer and highly dispersed silicon dioxide. Additional contents are initiators, stabilizers and pigments $(<1 \%)$. The primary particle size of the inorganic fillers is between $0.1 \mu \mathrm{m}$ and $7 \mu \mathrm{m}$. The mean particle size is $5 \mu \mathrm{m}$. The total content of inorganic fillers is approx. $40 \%$ vol.
Resin cement (dual-curing)
SpeedCEM ${ }^{\circledR} /$
Ivoclar Vivadent

\author{
(d)
}


while the remaining cervical $3 \mathrm{~mm}$ served as a guide to standardize the distance of the light-curing device from the cervical root region.

The root canal walls of all roots were etched with 37\% phosphoric acid gel (Total Etch, Ivoclar-Vivadent, Schaan, Liechtenstein). The gel was introduced in the canal through a needle, and rinsed after $15 \mathrm{~s}$ with water spray. Excess water was removed from the post space by gently blowing air into it and using paper points, leaving the dentin slightly moist. After this, an Excite DSC Endo microbrush (Ivoclar-Vivadent, Schaan, Liechtenstein) was used to apply two coats of the dualcure two-step etch-and-rinse adhesive to the root canal. A paper point was used to absorb the excess adhesive solution. The base and catalyst components of Variolink II (Ivoclar-Vivadent, Schaan, Liechtenstein) were then mixed, and the resin cement was introduced into the root canal space with a Centrix syringe (DFL, Rio de Janeiro, Brazil). After the fiber post was seated, the excess resin cement was removed, and the remaining cement was light-cured through the post for $40 \mathrm{~s}$.

All light-curing procedures were performed with a LED light-curing device (Radii Plus, SDI Limited, Victoria, Australia) using a power density of 1200 $\mathrm{mW} / \mathrm{cm}^{2}$. After post luting procedures, the roots with cemented posts were covered with conventional glass ionomer cement (Vitro Fil, DFL, Rio de Janeiro, Brazil), and all samples were stored in water at $37^{\circ} \mathrm{C}$ for 1 week.

\section{Push-out bond strength test}

After storage, the roots were placed in separate polyvinyl chloride (PVC) tubes and embedded in acrylic resin (Duralay, Illinois, USA). The portion of each root that contained the bonded fiber post was sectioned perpendicular to the long axis into six 1-mm thick slices. An Isomet 1000 (Buehler, Lake Bluff, USA) saw was used under water cooling to create two cervical, two middle, and two apical slices. Subsequently, all specimens were observed with a light stereomicroscope at $10 \times$ magnification in order to identify any artifacts caused by the sectioning procedure. If any defects were observed, the slices would be discarded.

The coronal side of each slice was identified and its thickness measured with a Mitutoyo digital caliper (Mitutoyo Digimatic Caliper, Tokyo, Japan) (accuracy of $0.01 \mathrm{~mm}$ ). The slices were also photographed on both sides, with an optical microscope (Olympus, model BX 51, Olympus, Tokyo, Japan) at 40× magnification to measure the internal coronal and apical diameters of the root canal walls, and calculate their individual bonding area. This measurement was taken with UTHSCSA ImageTool 3.0 software (Department of Dental Diagnostic Science at The University of Texas Health Science Center, Texas, USA).

Each specimen (slice) was subjected to a pushout BS test using a universal loading device (AG-I, Shimadzu Autograph, Tokyo, Japan) at a crosshead speed of $0.5 \mathrm{~mm} / \mathrm{min}$ with the load applied in the apical-coronal direction until the post was dislodged. Care was taken to center the push-out pin on the center of the root canal walls, without stressing the surrounding post space walls. With regard to the tapered design of the post, different sizes of punch pins were used matching the diameter of the root canal at the different root thirds being tested.

The maximum failure load was recorded in Newton (N) and converted into MPa by dividing the applied load by the bonded area $\left(\mathrm{S}_{\mathrm{L}}\right)$. As the bonded area was the lateral surface of a truncated cone, it was calculated by the formula:

$$
\mathrm{S}_{\mathrm{L}}=\pi(\mathrm{R}+\mathrm{r})\left[\left(\mathrm{h}^{2}+(\mathrm{R}-\mathrm{r})^{2}\right]^{0.5}\right.
$$

Where $\mathrm{R}=$ internal coronal radius of the root canal, $\mathrm{r}=$ internal apical radius of the root canal, and $\mathrm{h}=$ root slice thickness .

\section{Statistical Analysis}

The data were statistically analyzed by twoway repeated measures ANOVA (experimental groups and root region) and Tukey's test at a level of significance of 5\% using the Sigma Plot 11 software (Systat Software, San Jose, USA).

\section{Results}

None of the specimens presented artifacts caused by the sectioning procedure; therefore, none was discarded.

The mean ( \pm standard deviation) bond strength values, in $\mathrm{MPa}$, of the different groups are shown in Table 2. The cross-product interaction (experimental group vs. root region) was statistically significant 
Table 2. Mean values \pm standard deviation of bond strength (MPa) for the experimental groups.*

\begin{tabular}{lccc}
\hline \multirow{2}{*}{ Experimental groups } & \multicolumn{3}{c}{ Root region } \\
\cline { 2 - 4 } & Cervical & \multicolumn{1}{c}{ Middle } & Apical \\
\hline Positive control group & $16.4 \pm 3.9$ A & $12.3 \pm 1.6 \mathrm{~B}$ & $6.2 \pm 1.5 \mathrm{C}$ \\
\hline Negative control group & $3.7 \pm 0.6 \mathrm{E}$ & $2.9 \pm 0.7 \mathrm{E}$ & $1.7 \pm 0.3 \mathrm{E}$ \\
\hline Composite resin group & $7.2 \pm 1.0 \mathrm{C}$ & $5.2 \pm 0.6 \mathrm{D}$ & $2.8 \pm 0.6 \mathrm{E}$ \\
\hline Bulk-fill group & $7.6 \pm 1.1 \mathrm{C}$ & $6.0 \pm 0.6 \mathrm{C}$ & $5.1 \pm 1.1 \mathrm{C}, \mathrm{D}$ \\
\hline $\begin{array}{l}\text { Self-adhesive } \\
\text { cement group }\end{array}$ & $4.7 \pm 0.6 \mathrm{D}$ & $4.5 \pm 0.8 \mathrm{D}$ & $4.3 \pm 0.7 \mathrm{D}$ \\
\hline \begin{tabular}{l} 
Glass ionomer group \\
\hline
\end{tabular} & $3.1 \pm 0.7 \mathrm{E}$ & $2.5 \pm 0.8 \mathrm{E}$ & $1.9 \pm 0.4 \mathrm{E}$ \\
\hline
\end{tabular}

*Distinct letters show statistical significant differences $(p<0.05)$.

$(p<0.0001)$. The highest BS value was observed for the positive control group and the lowest BS values for the negative control group and the group with root reinforcement using glass ionomer cement. Among the root reinforcement techniques, the use of the flowable conventional resin and bulk-fill resin showed the highest BS values. However, the bulkfill resin was the only technique that provided high $B S$ values over all thirds of the root canal. The selfadhesive cement produced intermediate results between the conventional flowable resin and the glass ionomer cement.

\section{Discussion}

In the present study we confirmed that welladjusted posts are fundamental to provide a good adhesion to the root dentin, since highest BS values were obtained for the group with the thinnest layer of resin cement (positive control group), as observed in previous studies. ${ }^{17}$ Similarly, we observed the lowest BS value in the negative control group, in which a flared root canal had a prefabricated fiber post cemented without close adjustment to the root canals, rejecting the first null hypothesis. In that group, an excessive amount of resin cement was used to fill the areas between the post and root canal. Probably the lowest BS values for the groups with a thicker layer of resin cement, reflects the insufficient light transmission through the post to polymerize the entire cement layer. Although a dual-cure cement was employed, light activation is required to achieve a high degree of conversion. Dual-cure resin cements that polymerize only by chemical activation do not reach high levels of hardness and degree of conversion as those polymerized both chemically and by light. ${ }^{26,27,28}$ Thus, the polymerization of thick cement layers in deep regions may have relied only on the chemical activation produced by the self-cure component of the dual polymerization system.

Root reinforcement with restorative materials have been previously reported as an alternative to reduce the mismatch between prefabricated posts and flared root canals. ${ }^{8,13,29}$ In a study by Gomes et al. ${ }^{8}$ the authors found through the bond strength test that roots reinforced with a conventional composite resin resulted in low BS values, probably due to low polymerization at the deepest regions of the root canal. Therefore, the poor polymerization of lightcured resin may have been responsible for the low bond strength values reported in that study ${ }^{8}$ and fracture resistance ${ }^{13,29}$.

The material used in those studies ${ }^{8}$ is a conventional composite resin and as such should not be used in increments thicker than $2 \mathrm{~mm} \cdot{ }^{30}$ Roberts et al. ${ }^{11}$ evaluated the effect of a translucent post on the depth of cure of a conventional composite resin inside the root canal, concluding that hardness was considered effective up to $3 \mathrm{~mm}$ thickness. Yoldas et al. ${ }^{12}$, who worked with a simulated root canal, concluded that complete polymerization of the composite resin with translucent posts cannot be satisfactory in regions deeper than 4 to $5 \mathrm{~mm}$. Similarly, Teixeira et al. ${ }^{31}$ showed that resin hardness was significantly lower in deeper regions of roots with reinforcement and in lateral areas distant from the post. Indeed, this was also observed in the present study, as root reinforcement with a conventional composite resin showed lower bond strength values in the apical region of the root canal, rejecting the second null hypothesis.

The bulk-fill light-cured material used for root reinforcement showed similar performance than the conventional composite resin only in the cervical region. However, the bulk-fill resin was the only material able to maintain high bond strength values in the apical root third. The similar bond strength 
results in all root thirds can be attributed to the higher depth of cure ${ }^{17,21,23}$ and higher bond strength ${ }^{18}$ of these materials, when compared with conventional composite resin. To our extent, this is the first study that used bulk-fill composites for root reinforcement in flared root canal, which prevent us from comparing these results with other studies.

According to the manufacturer, the bulk-fill material is more translucent, which allows more light to pass through the body of the material. ${ }^{22}$ Additionally, the it contains the traditional camphorquinone/amine initiator system and the "initiator booster" (ivocerin), which are able to polymerize the material in deep locations. Ivocerin is described as a germanium-based initiator system with a higher photocuring activity than the camphorquinone/amine system because of its higher absorption in the wavelength region between 400 and $450 \mathrm{~nm}$ and ability to form at least two free radicals to initiate the radical polymerization. ${ }^{32}$

The lowest bond strength values of the glass ionomer group was expected, and was similar to the negative control group. Although this material is chemically cured, it does not present satisfactory mechanical properties. ${ }^{33}$ The results of this study contraindicate its use for root reinforcement of flared canals.

Phosphoric acid pretreatment increases the surface energy of the root dentin, removing the smear layer and surface contaminations and resulting in a thicker hybrid layer than the self-adhesive system. ${ }^{34}$ Therefore, bond strength of the etch-and-rinse system is superior to the self-adhesive cements. ${ }^{35}$ Corroborating these results, the self-adhesive cement showed higher values only compared with the negative control group and glass ionomer.

Clinically, dentists should keep the greatest possible amount of dentin structure prior to cementing a fiber post, as the positive control group showed the highest bond strength results. However, when necessary, root canal reinforcement with a bulkfill composite resin can attain higher bond strength values than the negative control group in all thirds of the root canal, and it is considered the technique of choice for root reinforcement of flared root canals.

However, the limitations of this study should be mentioned. All procedures were performed by a single calibrated operator with extensive clinical and academic experience. Thus, studies that evaluate the effect of operator experience and the variability of techniques may contribute to a better understanding of the clinical reality. Although well delineated, the study is laboratory-based and only randomized clinical trials can provide definitive evidence about the best technique for clinical use.

\section{Conclusion}

In teeth that need cementation of a fiberglass post, clinicians should attempt to maintain as much root dentin as possible, since a closely fit post exhibited the highest bond strength results. However, if this is not possible, root reinforcement with a bulk-fill composite resin is an effective technique for restoring flared root canals.

\section{Acknowledgements}

This study was partially supported by CAPES (Brazil). The authors are very grateful to the undergraduate students Otávio Augusto Ferreira Nóbile and Thaís Franz for their support with some laboratory steps and Ivoclar-Vivadent, 3M ESPE and FGM for donating of the materials used in this study. The authors deny any conflicts of interest related to this study.

\section{References}

1. Braem M, Lambrechts P, Van Doren V, Vanherle G.

The impact of composite structure on its elastic response. J Dent Res. 1986 May;65(5):648-53. https://doi.org/10.1177/00220345860650050301

2. Akkayan B, Gülmez T. Resistance to fracture of endodontically treated teeth restored with different post systems. J Prosthet Dent. 2002 Apr;87(4):431-7.

https://doi.org/10.1067/mpr.2002.123227

3. Coelho CS, Biffi JC, Silva GR, Abrahão A, Campos RE,

Soares CJ. Finite element analysis of weakened roots

restored with composite resin and posts. Dent Mater J. 2009

Nov;28(6):671-8. https://doi.org/10.4012/dmi.28.671 
Bond strength values of fiberglass post to flared root canals reinforced with different materials

4. Baba NZ, Goodacre CJ, Daher T. Restoration of endodontically treated teeth: the seven keys to success. Gen Dent. 2009 Nov;57(6):596-603.

5. Gomes GM, Rezende EC, Gomes OM, Gomes JC, Loguercio AD, Reis A. Influence of the resin cement thickness on bond strength and gap formation of fiber posts bonded to root dentin. J Adhes Dent. 2014 Feb;16(1):71-8. https://doi.org/10.3290/i.jad.a30878.

6. Clavijo VG, Reis JM, Kabbach W, Silva AL, Oliveira Junior OB, Andrade MF. Fracture strength of flared bovine roots restored with different intraradicular posts. J Appl Oral Sci. 2009 Nov-Dec;17(6):574-8. https://doi.org/10.1590/S1678-77572009000600007

7. Faria-e-Silva AL, Pedrosa-Filho CF, Menezes MS, Silveira DM, Martins LR. Effect of relining on fiber post retention to root canal. J Appl Oral Sci. 2009 Nov-Dec;17(6):600-4. https://doi.org/10.1590/S1678-77572009000600012

8. Gomes GM, Gomes OM, Gomes JC, Loguercio AD, Calixto $A L$, Reis A. Evaluation of different restorative techniques for filling flared root canals: fracture resistance and bond strength after mechanical fatigue. J Adhes Dent. 2014 Jun;16(3):267-76. https://doi.org/10.3290/i.jad.a31940.

9. Souza NC, Marcondes ML, Breda RV, Weber JB, Mota EG, Spohr AM. Relined fiberglass post: an ex vivo study of the resin cement thickness and dentinresin interface. Braz Oral Res. 2016 Aug;30(1):e77. https://doi.org/10.1590/1807-3107BOR-2016.vol30.0077

10. Zicari F, Couthino E, De Munck J, Poitevin A, Scotti R, Naert I et al. Bonding effectiveness and sealing ability of fiber-post bonding. Dent Mater. 2008 Jul;24(7):967-77. https://doi.org/10.1016/i.dental.2007.11.011

11. Roberts HW, Leonard DL, Vandewalle KS, Cohen ME, Charlton DG. The effect of a translucent post on resin composite depth of cure. Dent Mater. 2004 Sep;20(7):617-22. https://doi.org/10.1016/i.dental.2003.10.004

12. Yoldas $O$, Alaçam T. Microhardness of composites in simulated root canals cured with light transmitting posts and glass-fiber reinforced composite posts. J Endod. 2005 Feb;31(2):104-6. https://doi.org/10.1097/01.DON.0000133160.08600.47

13. Zogheib LV, Pereira JR, do Valle AL, de Oliveira JA, Pegoraro LF. Fracture resistance of weakened roots restored with composite resin and glass fiber post. Braz Dent J. 2008;19(4):329-33. https://doi.org/10.1590/S0103-64402008000400008

14. Gomes GM, Gomes OM, Reis A, Gomes JC, Loguercio AD, Calixto AL. Effect of operator experience on the outcome of fiber post cementation with different resin cements. Oper Dent. 2013 Sep-Oct;38(5):555-64. https://doi.org/10.2341/11-494-L

15. Skupien JA, Sarkis-Onofre R, Cenci MS, Moraes RR, Pereira-Cenci T. A systematic review of factors associated with the retention of glass fiber posts. Braz Oral Res. 2015;29(1):29. https://doi.org/10.1590/1807-3107BOR-2015.vol29.0074
16. Alshali RZ, Salim NA, Satterthwaite JD, Silikas N. Post-irradiation hardness development, chemical softening, and thermal stability of bulk-fill and conventional resin-composites. J Dent. 2015 Feb;43(2):209-18. https://doi.org/10.1016/i.jdent.2014.12.004

17. Czasch $P$, llie N. In vitro comparison of mechanical properties and degree of cure of bulk fill composites. Clin Oral Investig. 2013 Jan;17(1):227-35. https://doi.org/10.1007/s00784-012-0702-8

18. Flury S, Peutzfeldt A, Lussi A. Influence of increment thickness on microhardness and dentin bond strength of bulk fill resin composites. Dent Mater. 2014 Oct;30(10):1104-12. https://doi.org/10.1016/i.dental.2014.07.001

19. Algamaiah H, Sampaio CS, Rigo LC, Janal MN, Giannini M, Bonfante EA et al. Microcomputed tomography evaluation of volumetric shrinkage of bulk-fill composites in class II cavities. J Esthet Restor Dent. 2017 Apr;29(2):118-27. https://doi.org/10.1111/jerd.12275

20. Moharam LM, El-Hoshy AZ, Abou-Elenein K. The effect of different insertion techniques on the depth of cure and vickers surface micro-hardness of two bulk-fill resin composite materials. J Clin Exp Dent. 2017 Feb;9(2):e266-71. https://doi.org/10.4317/jced.53356

21. Ilie N, Keßler A, Durner J. Influence of various irradiation processes on the mechanical properties and polymerisation kinetics of bulk-fill resin based composites. J Dent. 2013 Aug;41(8):695-702. https://doi.org/10.1016/j.jdent.2013.05.008

22. Ilie N, Bucuta S, Draenert M. Bulk-fill resin-based composites: an in vitro assessment of their mechanical performance. Oper Dent. 2013 Nov-Dec;38(6):618-25. https://doi.org/10.2341/12-395-L

23. Benetti AR, Havndrup-Pedersen C, Honoré D, Pedersen MK, Pallesen U. Bulk-fill resin composites: polymerization contraction, depth of cure, and gap formation. Oper Dent. 2015 Mar-Apr;40(2):190-200. https://doi.org/10.2341/13-324-L

24. Kim RJ, Kim YJ, Choi NS, Lee IB. Polymerization shrinkage, modulus, and shrinkage stress related to tooth-restoration interfacial debonding in bulkfill composites. J Dent. 2015 Apr;43(4):430-9. https://doi.org/10.1016/i.jdent.2015.02.002

25. Internatinal Standardization for Organization. Guidance on testing of adhesion to tooth strucute. Geneve, Switzerland: 2003; CD TR 11405.

26. Acquaviva PA, Cerutti F, Adami G, Gagliani M, Ferrari M, Gherlone $\mathrm{E}$ et al. Degree of conversion of three composite materials employed in the adhesive cementation of indirect restorations: a micro-Raman analysis. J Dent. 2009 Aug;37(8):610-5. https://doi.org/10.1016/i.jdent.2009.04.001PMID:19450917

27. Arrais CA, Giannini M, Rueggeberg FA. Kinetic analysis of monomer conversion in auto- and dualpolymerizing modes of commercial resin luting cements. J Prosthet Dent. 2009 Feb;101(2):128-36. https://doi.org/10.1016/S0022-3913(09)60008-1 
28. Kim YK, Kim SK, Kim KH, Kwon TY. Degree of conversion of dual-cured resin cement light-cured through three fibre posts within human root canals: an ex vivo study. Int Endod J. 2009 Aug;42(8):667-74. https://doi.org/10.1111/j.1365-2591.2009.01565.x

29. Zogheib LV, Saavedra GS, Cardoso PE, Valera MC, Araújo MA. Resistance to compression of weakened roots subjected to different root reconstruction protocols. J Appl Oral Sci. 2011 Nov-Dec;19(6):648-54. https://doi.org/10.1590/S1678-77572011000600018

30. Braga RR, Ballester RY, Ferracane JL. Factors involved in the development of polymerization shrinkage stress in resin-composites: a systematic review. Dent Mater. 2005 Oct;21(10):962-70. https://doi.org/10.1016/j.dental.2005.04.018

31. Teixeira CS, Silva-Sousa YC, Sousa-Neto MD. Effects of light exposure time on composite resin hardness after root reinforcement using translucent fibre post. J Dent. 2008

Ju;36(7):520-8. https://doi.org/10.1016/i.jdent.2008.03.015

32. Moszner N, Fischer UK, Ganster B, Liska R, Rheinberger

$\checkmark$. Benzoyl germanium derivatives as novel visible light photoinitiators for dental materials. Dent Mater. 2008 Jul;24(7):901-7. https://doi.org/10.1016/i.dental.2007.11.004

33. Sidhu SK. Glass-ionomer cement restorative materials: a sticky subject? Aust Dent J. 2011 Jun;56 Suppl 1:23-30. https://doi.org/10.1111/j.1834-7819.2010.01293.x

34. Goracci C, Ferrari M. Current perspectives on post systems: a literature review. Aust Dent J. 2011 Jun;56 Suppl 1:77-83. https://doi.org/10.1111/j.1834-7819.2010.01298.x

35. Balkaya MC, Birdal IS. Effect of resin-based materials on fracture resistance of endodontically treated thinwalled teeth. J Prosthet Dent. 2013 May; 109(5):296-303. https://doi.org/10.1016/S0022-3913(13)60304-2 